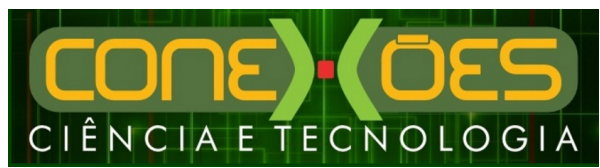

\title{
PERFIL DO IDOSO DA CIDADE DE CARIDADE-CE
}

\author{
Gabriela Fernandes Furtado ${ }^{1}$, Ana CARoline Lima Silva ${ }^{1}$, Letícia Lorrany Amorim \\ Aires Bittencour ${ }^{1}$, Taynara Miguel De Sous a Miguel Sousa ${ }^{1}$, Gabriela Aparecida \\ Alves Queiroz ${ }^{1}$, Erica IAnne Da Silva Sousa ${ }^{1}$, Isabel Cristina Paula Do Nascimento ${ }^{1}$
}

${ }^{1}$ Escola Estadual de Educação Profissional Francisco Paiva Tavares

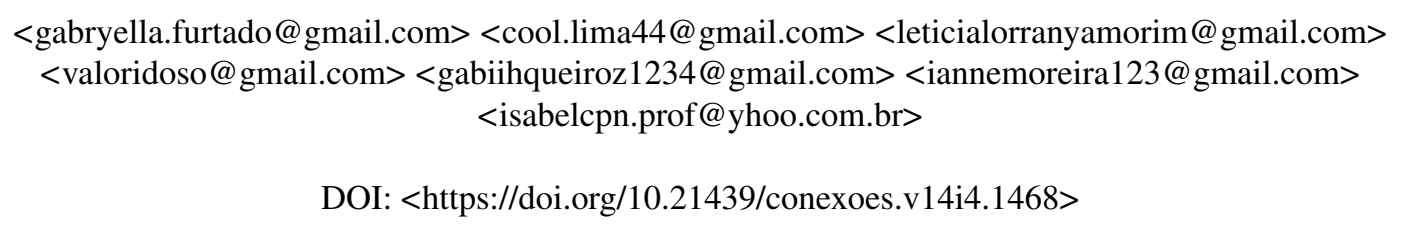

Resumo. O objetivo do presente artigo foi traçar o perfil do idoso de Caridade-CE, para servir como suporte de criação de políticas públicas e ações voltadas para as pessoas idosas. Afinal a quantidade de pessoas idosas terá um salto de 20 milhões, por volta dos 73,5 milhões no ano de 2060, existirá um idoso em cada três pessoas. O estudo foi de abordagem quantitativa, se caracterizou de forma transversal e de campo, através do questionário BOAS (adaptado). A pesquisa foi realizada nos domicílios da cidade de Caridade-CE. A amostra da pesquisa foi composta por 100 idosos residentes do município Caridade-CE (sede). Ao final do estudo realizado pode-se percebe-se um número maior de mulheres, com idades entre 60 a 70 anos, sendo todos os entrevistados cearenses. Alguns idosos compartilharam que sua cidade natal não era Caridade-CE, mas moram nesse município desde antes de sua emancipação política. O estudo mostra-se relevante, pois a população idosa exibe um elevado aumento, concomitante ao crescimento da desvalorização do indivíduo nessa fase da vida. O estatuto do idoso assegura os direitos das pessoas mais velhas, mas o que se percebe na sociedade é desrespeito e negligência com o idoso. É urgente a necessidade de mudanças de conceitos sobre o envelhecimento e resgate do respeito aos mais velhos.

Palavras-chaves: Perfil. Idoso. Caridade-CE.

\begin{abstract}
The objective of this article was to outline the profile of the elderly person of Caridade-CE, to serve as a support for creating public policies and actions aimed at elderly people. After all, the amount of elderly people will have a jump of 20 million, around the year 2060, there is an elderly person in three people. The study was of a quantitative approach, was characterized in a transversal and field way, through the questionnaire BOAS (adapted). The research was carried out in the homes of the city of Caridade-CE. At the end of the study, one can perceive a larger number of women, aged between 60 and 70 years, all of them being interviewed Ceará people. Some elderly people shared that their hometown was not Caridade, but they live in this city since their political emancipation. The study is relevant because the elderly population exhibits a high increase, concomitant to the growth of the devaluation of the individual at this stage of life. The statute of the elderly assures the rights of older people, but what is perceived in society is disrespect and neglects as the elderly. It is urgently necessary to change concepts about aging and to rescue respect for older people.
\end{abstract}

Keywords: Profile. Elderly. Caridade-CE 


\section{INTRODUÇÃO}

Segundo a Pesquisa Nacional por Amostra de Domicílios Contínua, a população brasileira ganhou 4,8 milhões de idosos desde 2012, superando a marca dos 30,2 milhões em 2017. Em 2012, os idosos com 60 anos ou mais era de 25,4 milhões. Os novos idosos (4,8 milhões) em cinco anos correspondem a um crescimento de $18 \%$, se tornando cada vez mais representativo no Brasil. As mulheres são maioria, com 16,9 milhões (56\% dos idosos), enquanto os homens idosos são 13,3 milhões (44\% do grupo).

A população idosa no Brasil, ao ser estudada, não se deve fugir da ideia de dupla constatação. Primeiramente, os múltiplos fatores que influenciam a numeração das pessoas que chegam a uma idade elevada são significativos e quanto mais tempo se passa esse número tende a crescer ainda mais. Logo em seguida como segunda questão, trata-se das condições de vida na qual a maioria da população tem que enfrentar logo ao nascer, para que os mesmos consigam sobreviver aos primeiros anos de vida e não cheguem a uma avançada idade mesmo com todas as provações e privações que é existente na sociedade. Para haver um processo de envelhecimento de qualidade, não depende somente das políticas públicas de saúdes já existentes, são necessários inúmeros fatores contributivos. Nesse processo será necessária uma maior insistência para com o poder público ofereça uma estrutura e atendimento de qualidade, fornecendo métodos para a extinção de preconceitos (BRASIL 2016).

Como o assunto envelhecimento, ganha espaço em projetos científicos, no ano de 1986, foi criado na Inglaterra o questionário Brazil Old Ege Schedule (BOAS), com o intuito de coletar informações sobre a população idosa, onde a primeira coleta de dados ocorreu no Rio de Janeiro. A apresentação dos resultados foi exposta por Renato Veras, tendo como segundo autor e coordenador no trabalho de campo Sidney Dutra. O questionário teve influência multidimensional que possibilitou a aplicação do mesmo em diversos locais do mundo sendo ele original ou adaptado fornecendo assim informações que sejam significativas mesmo com o passar dos anos (VERAS, 2008).

A população idosa exibe um elevado aumento, concomitante ao crescimento da desvalorização do indivíduo nessa fase da vida. $\mathrm{O}$ estatuto do idoso assegura os direitos das pessoas mais velhas, mas o que se percebe na sociedade atual é desrespeito e negligência no tratamento desses cidadãos. É urgente a necessidade de mudanças de conceitos sobre o envelhecimento e resgate do respeito aos mais velhos. O jovem precisa acordar e utilizar essa fonte inesgotável de conhecimentos, explorando estes tesouros muitas vezes desprezados pela sociedade. Torna-se necessária uma sensibilização da sociedade para o reconhecimento da velhice como uma etapa importante da vida dos seres humanos. O idoso precisa ter uma manutenção efetiva da sua autoestima e dos conhecimentos que são oportunizados durante todo o ciclo da vida. Imaginem quantos problemas seriam evitados se os adolescentes buscassem na sabedoria dos mais velhos, uma direção, um norte para suas vidas. Com isso a pesquisa teve como objetivo traçar o perfil do idoso de Caridade-CE, para servir como suporte de criação de políticas públicas e ações voltadas para as pessoas idosas.

\section{REFERENCIAL TEÓRICO}

\subsection{ENVELHECIMENTO NO SÉCULO XXI}

O Estatuto do Idoso (Lei $\left.n^{\circ} 10.741,2003\right)$ e a PNI - Política Nacional do Idoso (Lei no8. 842, 1994), define a pessoa idosa com 60 anos ou mais. Nota-se que o tempo cronológico da pessoa não é um referencial preciso para as mudanças que acompanham o envelhecer. Sabe-se da existência de alterações significativas na saúde, participação e independência entre seres humanos que tem a mesma idade (BRASIL, 2005).

Dias (2007) expõe que o envelhecimento é um processo subjetivo e multifatorial, na qual cada pessoa tem seu jeito de envelhecer. $\mathrm{O}$ ato de envelhecer é um conjunto de fatos que podem ser considerados além da idade, os fatores biológicos, fatores sociais, fatores econômicos, fatores intelectuais e fatores funcionais. $\mathrm{O}$ envelhecer contemporâneo sofreu diferentes mudanças quando comparado ao envelhecimento de antigamente, porém isso não é algo negativo. Conseguir superar os obstáculos desse século de inovações é essencial para o bem-estar dos idosos. É comum a visualização de notícias sobre pessoas idosas em situações precárias, a saúde pode ser considerada um dos principais desafios de envelhecer com qualidade na sociedade atual. É necessário a abolição de estereótipos sobre a terceira idade, afinal, os idosos precisam sentir-se úteis, considerando que a idade não é sinônimo de incapacidade (ROSA, 2015).

A população idosa no século XXI, tem uma longevidade maior, porém os desafios sociais, culturais, econômicos, políticos e a necessidade de promoção à saúde prevalece. Contudo, esse é o século em que esses problemas possivelmente serão resolvidos. A velhice atualmente é discutida como o "estágio" de mudanças, visando buscar a valorização necessária para que haja 
uma criação de ações para uma longevidade de qualidade (COSTA; SOUZA, 2013).

\subsection{PERFIL DO IDOSO}

Segundo Cedenho (2014), a velocidade do envelhecimento populacional é notória, porém esse aumento ocorre principalmente em países menos desenvolvidos, onde não existe tempo e nem condições para a existência de meios na construção de infraestrutura para ocorrer a frente uma importante e significativa transição social. Segundo o Instituto Brasileiro de Geografia e Estatística, os idosos representam quase 15 milhões de pessoas com 60 anos ou mais de idade $(8,6 \%$ da população brasileira). As mulheres são maioria, 8,9 milhões (IBGE, 2012).

O Brasil não se preparou para cuidar da população idosa, percebe-se o baixo número de universidades brasileiras que proporcionam cursos específicos para o cuidado com o idoso, sendo a formação profissional um dos aspectos relacionados a nova demanda na área da saúde. Quando constatada a ausência de política estruturada e articuladas para o envelhecimento, nota-se que a família é a primeira opção para o cuidado com o idoso. Vale ressaltar que o Estado tem contribuição mínima, muitas vezes resumidas à modalidade de abrigamento nas instituições de longa permanência para as pessoas idosas (asilos), que surgem por caridade de seres humanos que são sensibilizados por diversas situações com idosos em geral (PEREIRA, 2017).

\subsection{BRAZIL OLD AGE SCHEDULE (QUESTIONÁ- RIO BOAS)}

O BRAZIL OLD AGE SCHEDULE (Questionário BOAS) é um instrumento multidimensional, que abrange diversas áreas da vida da pessoa idosa (aspectos físicos e mentais, atividades do cotidiano, ocorrência sociais e econômicas). A ferramenta foi criada em 1986, na Inglaterra, para estudos que envolvesse os seres humanos pertencesses a terceira idade, através do mesmo, foi possível coletar dados que subsidiasse a primeira investigação da população idosa da cidade de Rio de Janeiro, esses resultados viraram tese de doutorado na Universidade de Londres, apresentados por Renato Veras, e coordenado (trabalho de campo), por Sidney Dutra (VERAS, 2008).

De acordo com Veras (2008), o nome do questionário teve, em parte, influência de onde foi elaborado, assim, o nome BRAZIL OLD AGE SCHEDULE (BOAS), tornou-se uma ótima sigla na língua portuguesa. Após 20 anos da sua invenção, esse questioná- rio junto com seu manual, tomou grande proporção e se tornou uma ferramenta aproveitada em estudos com populações idosas, seja em sua versão original ou adaptados a outras ferramentas para coleta de dados.

\section{ASPECTOS METODOLÓGICOS}

\subsection{Tipo de Pesquisa}

$\mathrm{O}$ estudo foi de abordagem quantitativa, na qual os resultados da pesquisa podem ser quantificados, se caracterizou de forma transversal e de campo, tendo como características as investigações além da pesquisa bibliográfica, com a realização de coleta de dados junto aos seres humanos) (GERHARDT; SILVEIRA, 2009).

\subsection{Local e Amostra}

A pesquisa foi realizada nos domicílios das pessoas idosas da cidade de Caridade - Ceará, localizados na sede. A amostra da pesquisa foi composta por 100 idosos, sendo $61 \%$ (feminino) e $39 \%$ (masculino) que são residentes do município Caridade-CE (sede).

\subsection{Critérios de Inclusão e Exclusão}

Poderiam participar da pesquisa os idosos que concordaram e assinaram o TCLE (Termo de Consentimento Livre e Esclarecido), e tinha idade de 60 anos ou mais. Não participaram da pesquisa as pessoas idosas que recusaram participar, não assinaram o TCLE e tinham idade inferior a 60 anos.

\subsection{Instrumentos}

Realizou-se inicialmente pesquisa bibliográfica sobre a temática, na qual foi tido conhecimento do Questionário BOAS (BRAZIL OLD AGE SCHEDULE) que, contém 76 perguntas, em seguida foi estudado e adaptado para 29 perguntas. Após, foi entregue aos idosos o termo de consentimento, que os mesmos preencheram e assinaram, que permite sua participação na pesquisa. A coleta aconteceu nas residências das pessoas idosas, em período diurno e noturno. As pesquisadoras recebiam os termos de consentimentos e iniciavam a aplicação do BRAZIL OLD AGE SCHEDULE - Questionário BOAS (VERAS, 2008) que consiste em um questionário que assegura elementos sobre as características, problemas e necessidades dos idosos.

\subsection{Análise dos Dados}

As informações coletadas foram tabuladas em uma planilha eletrônica (Excel - Windows 2010), apresentados em forma de gráficos e analisados posteriormente. 
PERFIL DO IDOSO DA CIDADE DE CARIDADE-CE.

\subsection{Aspectos Éticos}

A pesquisa respeitos os aspectos éticos, segundo o estabelecido pelo Conselho Nacional de Saúde (CNS), em conformidade com a Resolução $n^{\circ} 466 / 2012$ no que se refere à pesquisa com seres humanos. Os idosos pesquisados também assinaram o TCLE, que conta com informações detalhadas sobre o objetivo da pesquisa.

\section{RESULTADOS E DISCUSSÃO}

O Gráfico 1, mostra o sexo do entrevistado, sendo $61 \%$ (feminino) e $39 \%$ (masculino), totalizando 100 pessoas idosas. No caso, é perceptível que entre os entrevistados são em sua maioria mulheres.

Gráfico 1: Gênero da Amostra

\section{Sexo}

- a. Feminino = b. Masculino

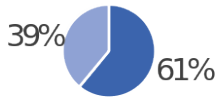

Segundo o IBGE, por meio da Pesquisa Nacional por Amostra de Domicílios - PNAD, no Brasil, a quantidade de mulheres chega a ser superior a quantidade de homens. O estudo realizado no ano de 2012, relata que somente no Brasil, cerca de 100,5 milhões são mulheres e somente 94,7 milhões são homens. Totalizando assim em todo o continente brasileiro $51,5 \%$ da população é composta por mulheres (NANÔ, 2012). Comparando o presente estudo com os dados do IBGE, (NANÔ, 2012 nota-se a predominância das mulheres no território nacional.

O Gráfico 2, apresenta a idade dos idosos, onde $72 \%$ tem 60 a 70 anos e $28 \%$ tem a partir de 71 anos. Nota-se que a maioria dos entrevistados estão com idade entre 60 anos a 70 anos.

Gráfico 2: Idade dos idosos

\section{Quantos anos o(a) Sr.(a) tem?}

- a. 60 à 70 anos $=$ b. 71 ou mais

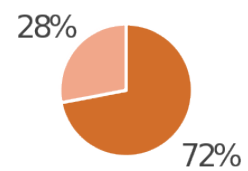

A quantidade de idosos no Brasil vem crescendo, especificamente entre os anos de 1991 e 2002 o número da população com sessenta ou mais anos de idade aumentou. Estudo feito pelo IBGE nos anos de 1992 e 2002 mostra o aumento de idosos com esse perfil aumentou cerca de duas e meia vezes mais, com $35 \%$ do que o resto da população do país com apenas $14 \%$. Vale ressaltar que no território brasileiro exceto a região norte, cerca de 29.976 idosos representam a população Brasileira com sessenta ou mais anos de idade (COSTA; BARRETO; GIATTI, 2003). Quando a presente pesquisa é comparada aos dados do IBGE, percebe-se o considerável aumento populacional dos idosos do nosso país.

O Gráfico 3, no qual representa a pergunta: Em que estado do Brasil o (a) S.r. (a) nasceu? Obteve o resultado que $100 \%$ nasceram no estado do Ceará. Concluindo assim que todos os entrevistados são cearenses.

Gráfico 3: Estado no nascimento

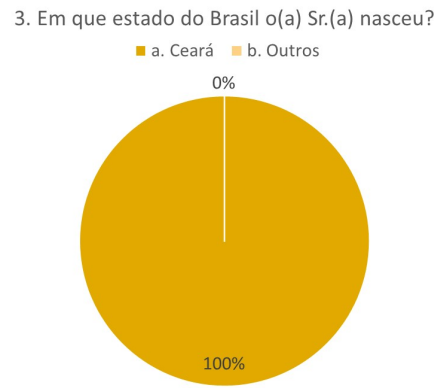

De acordo com a PNAD, onde a mesma realizou estudos no ano de 2011 sobre a estimativa da população Cearense, mostrou que a população do estado do Ceará é composta por 8.671 milhões de pessoas na qual, 1.089 são idosos $(12,6 \%)$ da população (LAVOR. 2012). Quando os dados da pesquisa são comparados ao PNAD, percebe-se o aumento da população cearense e predominância dos cearenses da cidade de CaridadeCE

No Gráfico 4, no qual representa a pergunta: Há quanto tempo(anos) o(a) Sr.(a) mora nesta cidade? 77\% dos entrevistados responderam que a mais de 21 anos, $12 \%$ até 10 anos, e $11 \%$ de 11 a 20 anos, nota-se que a maioria dos idosos entrevistados residem em CaridadeCE há mais de 21 anos.

A cidade de Caridade-CE, completou 60 anos de emancipação política. No momento da entrevista, alguns idosos compartilharam que sua cidade natal não era Caridade - CE, eram originados da Serra de Guara- 
Gráfico 4: Tempo de moradia

4. Há quanto tempo (anos) o(a) Sr.(a) mora nesta cidade?

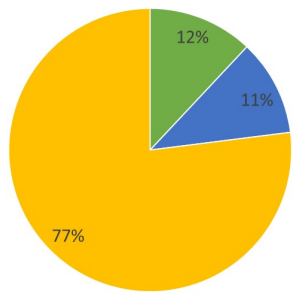

miranga, que fica há $28,11 \mathrm{~km}$ de distância da cidade atual, pois buscavam melhores condições financeiras. Alguns idosos moram nesse município mesmo antes de sua emancipação política.

O Gráfico 5 representa se o idoso sabe ler e escrever. Onde $51 \%$ disseram que não e $49 \%$ disseram que sim. O gráfico mostra que a maioria dos idosos não sabem ler e escrever.

Gráfico 5: Leitura e Escrita

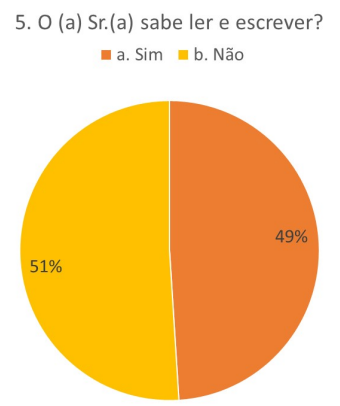

Segundo o IBGE no censo de 2000, a maioria da população brasileira não era alfabetizada, dentre eles especificamente os idosos, sabe-se que existem instituições educacionais para crianças e adolescentes e até mesmo para adultos trabalhadores de industrias, como é o caso do EJA. Porém, mesmo com a existência do EJA o número de idosos analfabetos é elevado (PERES, 2011).

Segundo a Constituição Federal (1988), no art. 208, o Estado tem dever com a educação mediante a garantia da educação básica obrigatória e gratuita, para os seres humanos que não tiveram acesso na idade própria; ou seja, todos tem o direito a educação independe da idade. Comparando os resultados da presente pesquisa com o IBGE e a Constituição Federal (1988), percebe-se que a educação é para todos, sendo contraditório o número elevando de pessoas analfabetas, e ainda sua maioria pessoas idosas.

O Gráfico 6 representa a escolaridade dos idosos. Onde $61 \%$ tem o ensino fundamental incompleto, $26 \%$ são analfabetos, $4 \%$ ensino fundamental completo, $4 \%$ possuem ensino médio completo, $3 \%$ possuem ensino médio incompleto e $2 \%$ tem o nível superior. Percebese que a maioria não conseguiu completar o ensino fundamental.

Gráfico 6: Escolaridade

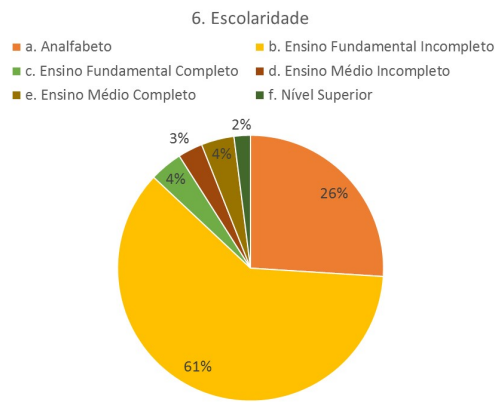

Historicamente, na década de 60 no processo de direitos sociais os homens tinham mais acesso ao estudo do que as mulheres, em vista disso o IBGE relata que no Brasil, os homens têm maiores níveis de escolaridade do que as mulheres. Entre 1991 a 2000 os aumentos tanto na proporção de alfabetizados, como também nos níveis de escolaridade foram significativos, porém isso não significa que o problema da escolaridade foi resolvido, a questão da escolaridade dos idosos na sociedade atual tem sua relevância e precisa ser levado em consideração. Comparando os estudos dessa pesquisa com o IBGE, nota-se que o índice de alfabetação cresceu, concordando com os dados dessa pesquisa, afinal, a maior concentração dos pesquisados estão com o ensino fundamental incompleto (IBGE, 2012).

No Gráfico 7, na qual representa a pergunta: Atualmente, qual é o seu estado conjugal? $45 \%$ dos entrevistados são casados ou moram juntos, $26 \%$ são divorciados ou separados, $23 \%$ são viúvos, e $6 \%$ nunca casaram. A maioria dos idosos questionado relatam que ainda são casados e estão morando juntos.

De acordo com o IBGE, a quantidade de pessoas casadas ultrapassa o número de pessoas solteiras entre a população brasileira, ao passo que a PNAD, estimouse que dentre os 145,3 milhões de habitantes, 45,8\%, ou seja 66,6 milhões de pessoas eram casadas. Comparando com os resultados dessa pesquisa, percebe semelhança de resultados, afinal, a existência de seres humanos casados é maior (SARAIVA, 2010). 


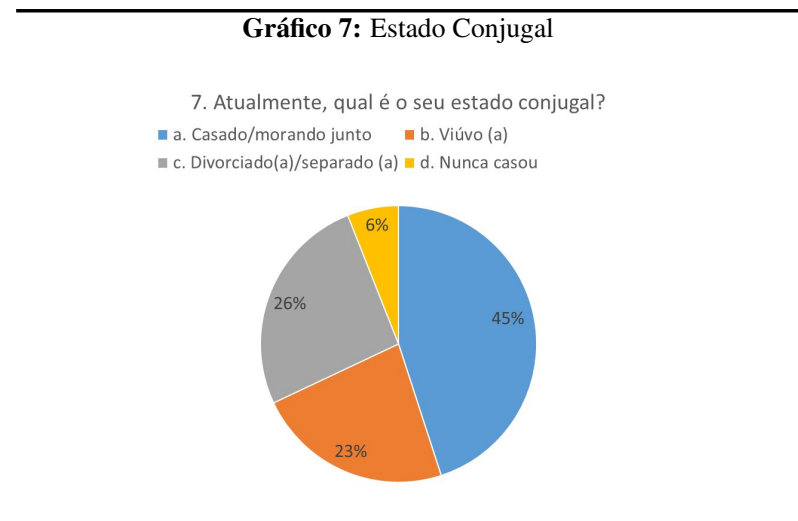

O Gráfico 8, no qual representa a pergunta: $\mathrm{O}$ (a) $\mathrm{Sr}$. (a) teve filhos? Se sim, quantos? Na qual $79 \%$ responderam que tiveram 4 ou mais, $9 \%$ eles responderam que tiveram 1 ou 2 filhos e por fim com $3 \%$ os entrevistados responderam que tiveram 3 filhos. A maioria dos pesquisados tiveram 4 filhos ou mais.

\section{Gráfico 8: Filhos}

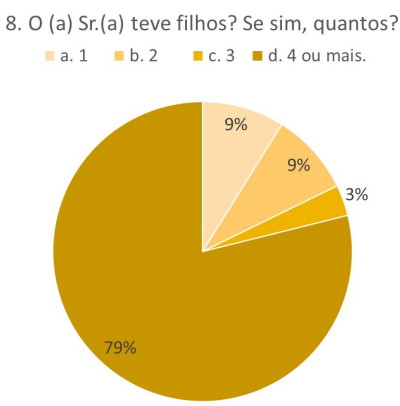

É notório que a alguns anos a população não tinha acesso a qualquer tipo de políticas públicas relacionado a formação familiar. Historicamente, o elevado número de filhos não era considerado um problema, já que muitas crianças não sobreviviam ao primeiro ano de nascimento. Com o passar dos anos e os surgimentos de novas políticas públicas e ao mesmo tempo novas tecnologias especificamente dos meios de produções nos períodos das revoluções industriais, aonde as mulheres tiveram o direito de ter uma inclusão no mercado de trabalho, gerando assim novas configurações familiares (SOUZA; NORONHA; SILVA, 2016). Percebe-se semelhança entre os estudos, pois os idosos de Caridade - CE tem um número elevado de filhos, comparado as estruturas familiares contemporânea.

O Gráfico 9 , representa se atualmente os idosos estão satisfeitos ou não em relação a sua vida onde $91 \%$ estão satisfeitos e $9 \%$ insatisfeitos. Os dados mostram que a maioria dos idosos entrevistados estão satisfeitos com sua vida.

Gráfico 9: Sentimento com a vida

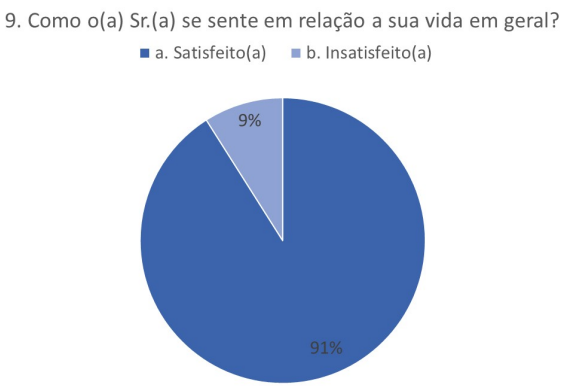

Segundo Vale (2010), muitos idosos se sentem satisfação ao participarem da terceira idade, muitos decidem não ficar parados e vão em busca de novas experiências e essa questão é literalmente benéfica a saúde. Porém, outra parcela da população idosa, sente-se incapaz de realizar qualquer atividade, pois os mesmos pensam que por fazerem parte da terceira idade é inexistente a possibilidade de diversão, já que para eles, a época de diversões e realizações de sonhos passaram, associando assim relação total com os resultados dessa pesquisa.

No Gráfico 10, descreve como os idosos diriam a sua saúde está, na qual 54\% responderam que está boa, $29 \%$ responderam que está ruim, $12 \%$ responderam que está ótima e 5\% responderam que está péssima.

Gráfico 10: Saúde do Idoso

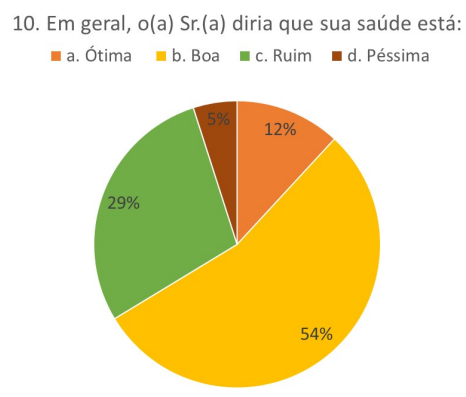

De acordo com Ramos (2002), a saúde dos idosos está diretamente ligada a questões sociais, incluindo a convivência e formas de tratamentos dos familiares para com os idosos. Essa questão tem lados positivos como a demonstração de carinho e afeto que para alguns idosos é algo que ajuda a diminuir o estresse, já para outra parcela de idosos a baixa autoestima, o sentimento de inutilidade acaba fazendo com que as mesmas venham 
PERFIL DO IDOSO DA CIDADE DE CARIDADE-CE.

a ter depressão que traz consigo vários efeitos negativos para com a saúde. Comparando o estudo de Ramos, com a presente pesquisa, percebe-se que os idosos de Caridade - CE, consideram sua saúde boa, os mesmos podem se sentir bem tratados pelas pessoas que convivem com eles, afinal, a saúde do idoso está relacionada com o tratamento para com os mesmos.

O Gráfico 11, no qual representa a pergunta: Atualmente o(a) Sr.(a) tem algum problema de saúde? Em sua maioria com $65 \%$ responderam que sim, e o restante com $35 \%$ responderam que não tem problema de saúde.

Gráfico 11: Problemas de Saúdes

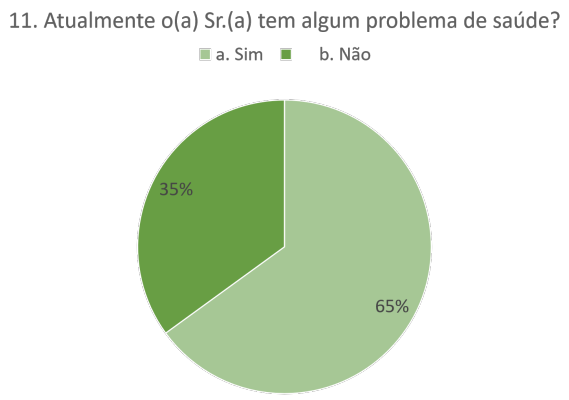

Segundo Jacob Filho (2017), algumas pessoas associam o avançar da idade à acumulação de doenças, supondo que ao prosseguir com a idade, as pessoas terão que conviver com problemas de saúde e limitações. Em comparação o estudo de Jacob Filho com o presente estudo, nota-se a semelhança, pois a maioria dos pesquisados relatam algum problema de saúde.

O Gráfico 12, noig qual representa a pergunta em geral; $\mathrm{O}$ (a) Sr.(a) diria que sua visão (com ou sem a ajuda de óculos) está: Com $43 \%$ dos entrevistados responderam que sua visão está boa, $30 \%$ responderam que está ruim, 19\% responderam que está ótima, $6 \%$ responderam que está péssima e $2 \%$ responderam que não enxerga.

Segundo Mendes (2008), o que mais afeta as pessoas idosas é a sua falta de visão que vai ficando prejudicada com o passar do tempo, o órgão ocular é afetado de todas as formas, interna ou externa, poeira, exposição a luz, entre outros. Comparando os dois estudos, percebe-se diferença entre as pesquisas, afinal, a maioria dos pesquisados do presente estudo consideram sua visão boa, mas pode-se considerar os $30 \%$ que consideram sua visão ruim.

O Gráfico 13, no qual representa a pergunta: Em geral, o(a) Sr.(a) diria que sua audição (com ou sem a ajuda de aparelhos) está: $45 \%$ responderam que está
Gráfico 12: Visão dos Idosos

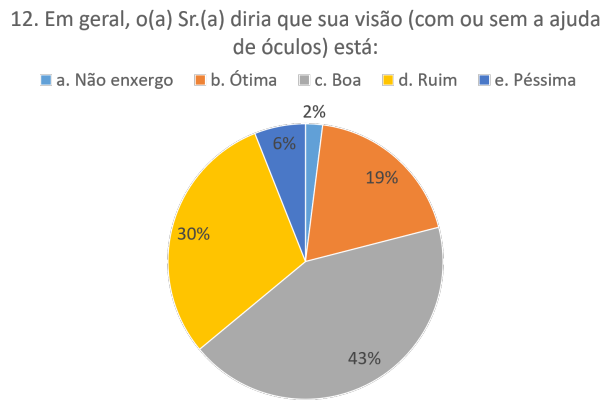

ótima, com $43 \%$ responderam que está boa, $10 \%$ responderam que está ruim e $2 \%$ responderam que está péssima e nenhum dos entrevistados responderam que não escutam.

Gráfico 13: Audição dos Idosos

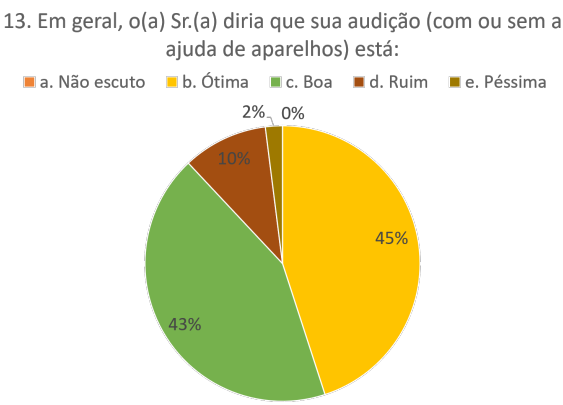

Segundo Dib (2006), enquanto ciência a fonologia se interessa em estudar assuntos que diz respeito aos idosos, especificamente relacionado a sua audição e a perda dela com o passar do tempo. A perda de audição ou presbiacusia é um dos casos crônicos que mais encontrados nos idosos, essa questão implica diretamente em mudanças físicas, psicologias e sociais na vida dessas pessoas, acarretando assim efeitos devastadores na vida dos mesmos relacionado a comunicação e convivência familiar. No estudo de Dib, a perda de audição ou presbiacusia, pode ser um dos casos crônicos mais encontrados nas pessoas idosas, já o presente estudo mostra que os idosos em sua maioria consideram sua audição boa e ótima.

O Gráfico 14 no qual representa a pergunta: Quando o Sr.(a) está doente ou precisa de atendimento médico, onde ou a quem o(a) Sr.(a) normalmente procura? A maioria com $77 \%$ respondeu que procuram o serviço médico de uma instituição pública gratuita, $10 \%$ responderam que procuram o serviço médico cre- 
denciado pelo seu plano de saúde, $10 \%$ responderam que procuram médicos/clinicas particulares e com $3 \%$ ninguém ou o entrevistado não procura o médico há muito tempo. A maioria dos entrevistados procuram serviço médico em uma instituição pública gratuita.

Gráfico 14: Atendimento Médico

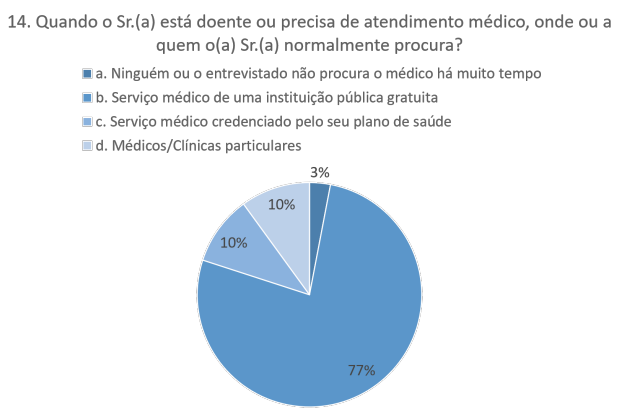

Quando se fala em direito a saúde do idoso, o Estatuto do Idoso, expressa claramente no, Art. 15 que é garantida a atenção integral à saúde da pessoa idosa pelo SUS (Sistema Único de Saúde), sistema gratuito. Realizando uma análise entre os dois estudos, percebe-se que a maioria dos entrevistados procuram serviço médico de instituições públicas gratuita, fazendo valer seus direitos assegurados por LEI (BRASIL, 2012).

O Gráfico 15, no qual representa pergunta: $\mathrm{O}(\mathrm{a})$ Sr.(a) está satisfeito com os serviços médicos que utiliza normalmente? A maioria com $88 \%$ respondeu que sim, $11 \%$ responderam que não e $1 \%$ não utiliza serviços médicos ou não precisa consultar medica há muito tempo.

Gráfico 15: Satisfação dos serviços médicos

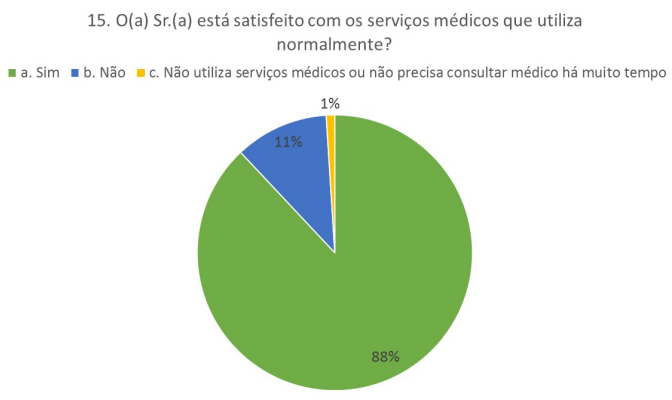

Segundo ??), mesmo com todos os direitos que a população idosa conquistou, a questão do atendimento à saúde é algo complexo. Porém o governo do brasil relacionado ao atendimento básico criou o programa de expansão do atendimento médico, que visa beneficiar as periferias das cidades e interiores do país, melhorando assim a acessibilidade e qualidade dos atendimentos nesses locais. Assim, ao associar os dois estudos, nota-se essa melhoria em Caridade-CE, afinal, a maioria dos idosos caridadenses estão satisfeitos com os atendimentos médicos do município.

No Gráfico 16 no qual representa a pergunta: O (a) Sr.(a) toma remédio? A maioria com $80 \%$ respondeu que sim e o restante com $20 \%$ responderam que não.

Gráfico 16: Uso de medicamentos

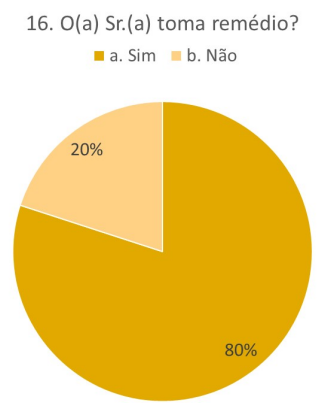

Segundo Azevedo (2017), cerca de 25\% das vendas de medicamento são para as pessoas que integram a terceira idade. Comparando o presente estudo com o de Azevedo, percebe-se semelhança de resultados, pois a terceira idade se torna consumidora de medicamentos e a maioria dos entrevistados utilizam os mesmos.

O Gráfico 17, no qual representa a pergunta: No caso de o(a) Sr.(a) ficar doente ou incapacitado(a), que pessoa poderia cuidar do(a) Sr.(a)? A maioria com $39 \%$ respondeu que seria o filho(a), 24\% disseram que seria outra pessoa de fora da família, $18 \%$ responderam que nenhuma, $17 \%$ responderam que esposo(a)/companheiro(a) e com $2 \%$ responderam que outra pessoa da família.

Gráfico 17: Cuidados com o idoso

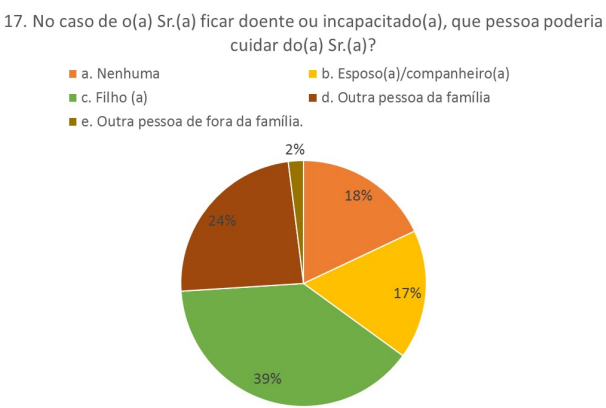

Segundo O Art. $3^{\circ}$ do Estatuto do idoso, consta que 
PERFIL DO IDOSO DA CIDADE DE CARIDADE-CE.

é obrigação de todos (família, comunidade, sociedade e Poder Público) garantir a pessoa idosa prioridade, efetivação, saúde, alimentação, educação, cultura, esporte, lazer, trabalho, cidadania, liberdade, dignidade, respeito e à convivência familiar e comunitária (BRASIL 2003). Comparando os estudos, nota-se que a maioria dos entrevistados consideram que podem contar com seus filhos, afirmando o que está escrito no estatuto do idoso, mas um dado que chama a atenção, são os $18 \%$ que responderam que não podem contar com ninguém, lembrando que é direito do idoso ser cuidado, quando o mesmo necessita disso, tornando-se assim, esse valor alarmante, podendo explicar a criação de diversos lares que existem atualmente e o crescente abandono de pessoas idosas.

O Gráfico 18, diz respeito a capacidade dos entrevistados de fazerem determinadas atividades. 95\% responderam que conseguem comer a sua refeição sozinho e 5\% responderam que não conseguem. 93\% responderam que conseguem tomar banho sozinhos e $7 \%$ responderam que não. $90 \%$ responderam que conseguem tomar seus remédios, vestir-se e pentear seus cabelos sozinhos e $10 \%$ responderam que não conseguem. $85 \%$ responderam que conseguem sair de casa sozinhos e $15 \%$ responderam que não conseguem. $81 \%$ responderam que conseguem cortar as unhas dos pés e $19 \%$ responderam que não conseguem. $76 \%$ responderam que conseguem preparar sua própria refeição sozinhos e $24 \%$ responderam que não. $69 \%$ responderam que conseguem deitar e levantar da cama sozinhos e $31 \%$ responderam que não conseguem. 53\% responderam que conseguem arrumar a casa sozinhos e $47 \%$ responderam que não conseguem.

Gráfico 18: Capacidade de realização de atividades.

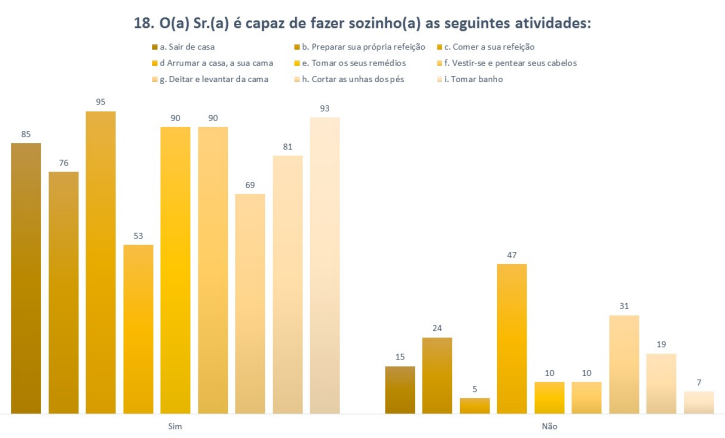

Segundo ??), a maioria dos idosos moram sozinhos e são responsáveis pelas atividades diárias, os mesmos são responsáveis ao cuidar da própria saúde tendo a consciência de quais remédios devem ser tomados, com um número elevado de idosos no país os mesmos tendo capacidade de fazerem essas atividades é, no entanto, um privilégio.

Segundo (??), os idosos do século atual estão mais independentes, indo em buscas de novas experiências e também buscando a melhoria da própria saúde. A fragmentação ou maior dispersão das famílias faz com que os pais tenham maior preocupação com eles próprios por morarem sozinhos já que nesse período muitos filhos vão trabalhar em outras cidades.

Comparando o presente estudo com os estudos de Cabanas e Santos, percebe-se a independência dos idosos na realização de diversas atividades, considerando a maioria dos idosos caridadense independentes, pois conseguem realizar atividades do cotidiano em sua maioria sozinhos.

O Gráfico 19 diz respeito ao tempo livre dos entrevistados, na qual $78 \%$ responderam que ouvem a radio e $22 \%$ responderam que não. $86 \%$ responderam que assistem a televisão e $14 \%$ não assistem televisão. $81 \%$ responderam que não leem jornal, revistas e livros e $19 \%$ responderam que sim. $86 \%$ responderam que recebem visitas ou sai para visitar amigos ou parentes e $14 \%$ responderam que não. $64 \%$ responderam que andam pelo bairro e $36 \%$ responderam que não. $77 \%$ responderam que vão a igreja e $23 \%$ responderam que não. $68 \%$ responderam que não costuram, bordam, tricotam e $32 \%$ responderam que sim. $66 \%$ responderam que fazem compras e $34 \%$ responderam que não. 52\% responderam que fazem alguma atividade para se distrair e $48 \%$ responderam que não.

Gráfico 19: Tempo livre do idoso

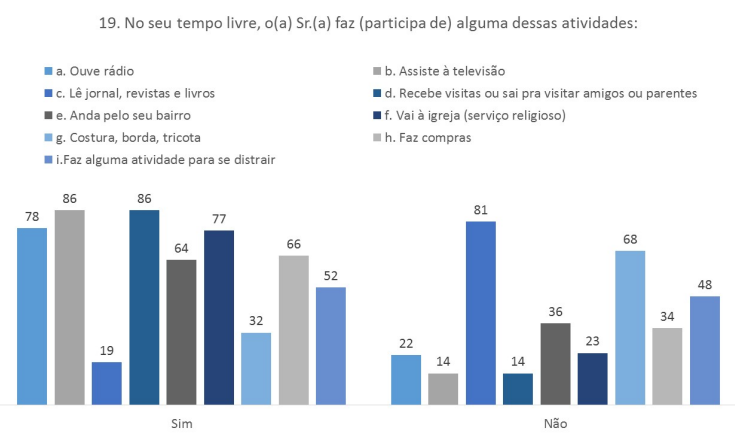

Segundo Teixeira (2007), a necessidade do lazer é uma necessidade humana na qual traz a marca das condições sócio históricas onde uma possível satisfação dessa necessidade ou acesso está definida pela ocupação do lugar na divisão social do trabalho. De acordo com Nogueira e Martins (2017), é necessário estimu- 
PERFIL DO IDOSO DA CIDADE DE CARIDADE-CE.

lar o idoso a realização de atividades de lazer, em vista que aqueles que passam boa parte do tempo sem nenhum tipo de ocupação podem sofrer com algum tipo de doença do corpo ou da mente. Quando o atual estudo é comparado com os de Teixeira, Nogueira e Martins, percebe-se a importância do lazer para a pessoa idosa, vale ressaltar que a maioria dos idosos da cidade de Caridade-CE, utilizam seu tempo livre para ouvir rádio, assistir televisão, receber e realizar visitas e irem para a igreja.

O Gráfico 20, diz respeito se os entrevistados estão satisfeitos com o relacionamento que os mesmos têm com as pessoas que moram com eles. $84 \%$ respondeu que sim, $14 \%$ responderam que moram sozinhos e $2 \%$ responderam que não. A maioria dos entrevistados responderam que estão satisfeitos com o relacionamento com as pessoas que moram com eles.

Gráfico 20: Relacionamento com as pessoas que moram com os idosos

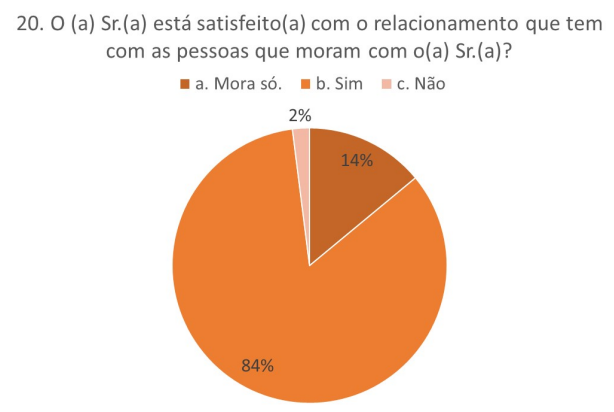

O relacionamento é uma expressão que engloba as relações do homem com seus semelhantes em seu significado pelo processo comunicativo verbal ou não verbal. Esse relacionamento família/idoso está diretamente ligada com o processo de comunicação no entanto interpessoal entre seus integrantes (COSTA; MADEIRA 1994). Comparando a pesquisa atual com o estudo de Costa e Madeira, nota-se que boa comunicação entre os pesquisados e seu familiares, pois os mesmos estão satisfeitos com esse relacionamento.

O Gráfico 21. diz respeito a satisfação dos entrevistados com o relacionamento que os mesmos têm com seus vizinhos e amigos. A maioria dos entrevistados com $95 \%$ respondeu que sim e $5 \%$ responderam que não.

Existe duas formas de oferecer o suporte social que o idoso necessita, nesse caso especifica-se as redes de apoio informal, onde os representantes além da família são os vizinhos e amigos que dão apoio em diferentes setores da vida do idoso (ARAÚJO et al., 2012). Em

\section{Gráfico 21: Relacionamento com vizinhos e amigos}

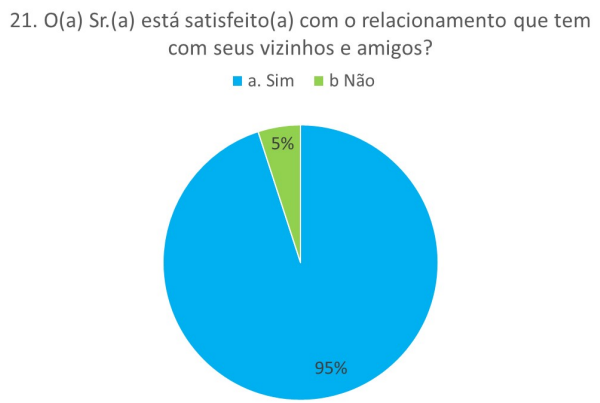

comparação a pesquisa atual com o estudo de Araújo et. al., percebe-se o suporte social que os idosos caridadenses têm, pois estão satisfeitos com o relacionamento existente entre vizinhos e amigos.

O Gráfico 22, representa a seguinte pergunta: De onde o(a) Sr.(a) tira o sustento de sua família? $70 \%$ não tiram do seu trabalho, $30 \%$ sim. $88 \%$ dos entrevistados responderam que tiram o sustento da sua aposentadoria e $12 \%$ responderam que não. $82 \%$ responderam que não tiram o seu sustento da pensão/ajuda do(a) seu(sua) esposo(a), $18 \%$ responderam que sim. $89 \%$ dos entrevistados responderam que não tiram sustendo da ajuda de parentes ou amigos, já $11 \%$ responderam que sim. $90 \%$ dos entrevistados responderam que tiram seu sustento de alugueis, investimentos, e $10 \%$ responderam que sim.

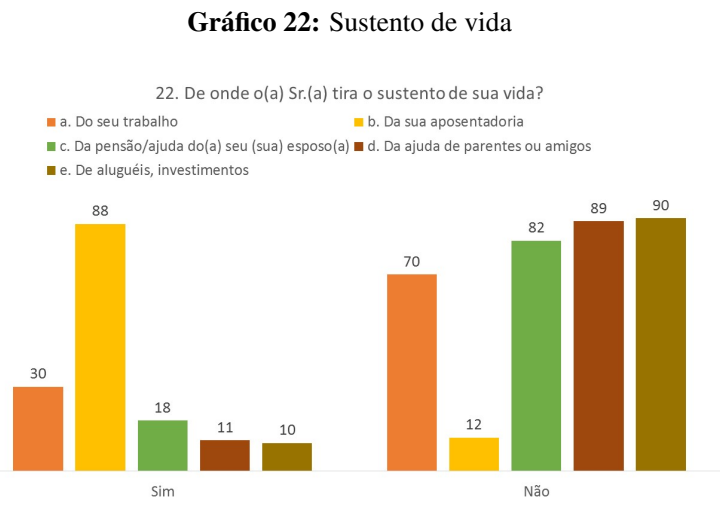

Segundo o IBGE no censo de 2000, ao passo que a quantidade de idosos no Brasil aumenta, também cresce a quantidade de idosos responsáveis pelos domicílios e consequentemente o sustento de suas famílias. Comparando o presente estudo com os dados que o IBGE divulga, nota-se semelhança, pois a maioria dos idosos contemporâneos sustentam suas famílias com a sua aposentadoria. 
PERFIL DO IDOSO DA CIDADE DE CARIDADE-CE.

O Gráfico 23, diz respeito se o que os entrevistados ganham dá para as suas necessidades básicas. 54\% responderam que o que ganham dá na conta certa. $26 \%$ responderam que dá e sobra, $15 \%$ responderam que sempre falta um pouco, com $5 \%$ responderam que sempre falta muito. É perceptível que a maioria respondeu que dá na conta certa.

Gráfico 23: Necessidades Básicas

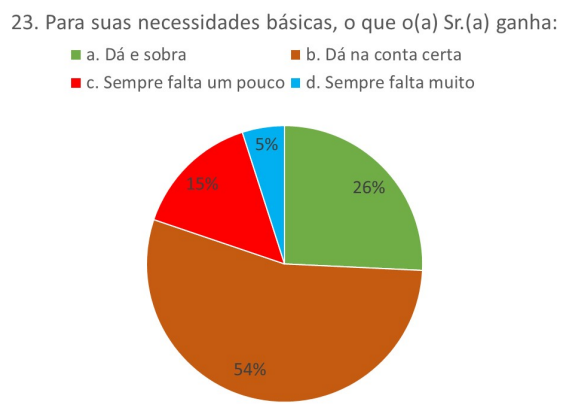

Segundo Evans (2015), o aumento da aposentadoria não é significativo, pois não passa de um salário mínimo e isso acaba prejudicando a vida dos idosos, afinal, quanto mais tempo se passa, mais despesas os mesmos têm, a ponto de os idosos enfrentarem uma fase mais difícil do que os jovens. Quando os estudos são comparados, percebe-se que a maioria dos idosos caridadenses demonstram que o dinheiro do seu sustento da pra contas certas do mês. Assim, se diferenciando do estudo de Evans, afinal, os idosos conseguem pagar suas contas.

O Gráfico 24, diz respeito aos arrependimentos dos entrevistados a anos anteriores de sua vida. $72 \%$ responderam que não tem arrependimento, $16 \%$ responderam que se arrependem, mas não se culpam, $8 \%$ responderam que se arrependem, culpam-se, mas que atualmente não pensam no assunto, $4 \%$ responderam que se arrependem, culpam-se e pensam muito no assunto. Percebe-se que a maioria não possui nenhum arrependimento.

Segundo Jeremias (2015), ao ler uma coluna escrita por Karl A. Pillemer, que compartilhou 2 mil depoimentos de pessoas idosas com quem conversou durante os últimos dez anos, que tinha como objetivo inspirar a juventude a viver vidas sem arrependimentos. Quando comparamos o estudo de Jeremias com a atual pesquisa, percebe-se que os idosos não estão se arrependendo de ações desenvolvidas em anos anteriores da sua vida, isso pode ocorrer pela nova geração de idosos que estão sendo formadas, idosos que sabem viver intensamente

\section{Gráfico 24: Arrependimento em anos anteriores}

24. O(a) Sr.(a) tem algum arrependimento em relação aos anos anteriores da sua vida?

- b. Arrepende-se, mas não se culpa.

- c. Arrepende-se, culpa-se, mas atualmente não pensa no assunto.

Ind Arrepende-se, culpa-se e pensa bastante sobre o assunto.

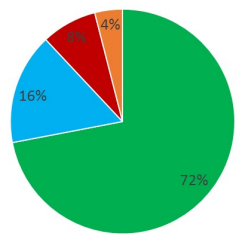

diversos momentos de suas vidas.

O Gráfico 25, diz respeito as expectativas de futuro dos entrevistados. $56 \%$ responderam que mencionam expectativas e pensam no futuro, $37 \%$ não mencionam expectativas, mas também não refere a nenhuma afirmação negativa, $7 \%$ responderam que o futuro é descrito negativamente ou amedrontador ou insuportável. É notório que a maioria dos entrevistados mencionam expectativas e pensam no futuro.

Gráfico 25: Expectativas para o futuro

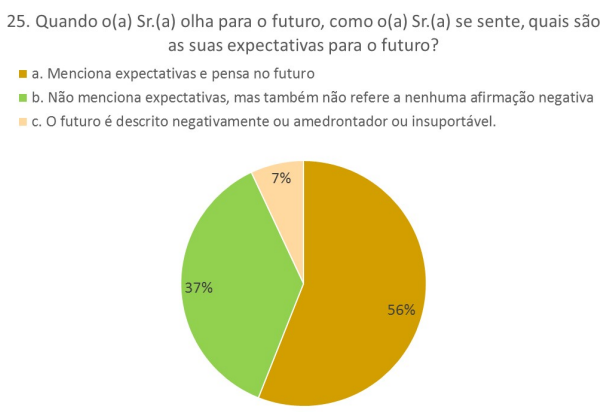

Segundo (Sé, 2015), a velhice está carregada de avaliações positivas e negativas, existindo diferentes itinerários para o envelhecimento, é preciso evitar pensamentos dicotômicos. Quando se fala que os idosos não planejam metas, não conseguem objetivos futuros e não concretizam sonhos, estamos sendo preconceituosos. Quando comparamos a presente pesquisa com o estudo de Sé, percebe-se a necessidade que o ser humano tem de se projetar em um futuro, e buscar expectativas e com os idosos caridadenses não foi diferente.

O Gráfico 26 diz respeito a felicidade dos entrevistados nos dias atuais. $84 \%$ responderam que sim, estão felizes nos dias atuais. $16 \%$ responderam eu não. É notório que a maioria dos entrevistados estão felizes atualmente. 


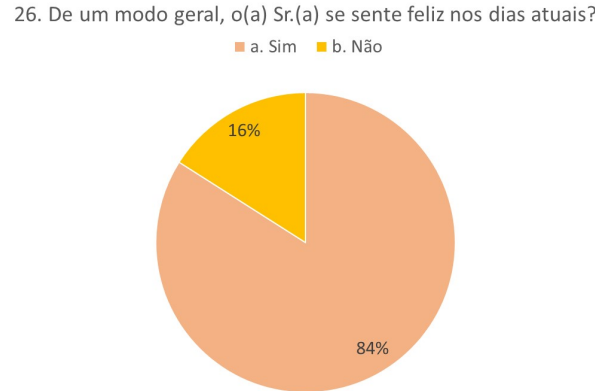

Um estudo realizado em Campinas - São Paulo, no ano de 2008, analisou seres humanos de 60 anos ou mais de idade, incluindo questões de felicidade. Através do estudo foi identificado que o sentimento de felicidade esteve presente por todo o tempo, com concentração maior nos idosos que ainda trabalham, que moderam na ingestão de bebida alcoólica, ativos ou não ativos no lazer, consumidores de frutas, legumes e verduras todos os dias (LIMA; BARROS; ALVES, 2012). Quando compramos os estudos de Lima, Barros e Alves com o presente estudo, nota-se que há predominância de idosos felizes, mas quando analisamos os motivos que causam essa felicidade, percebe-se diferença em relação aos idosos que ainda trabalham e alguns motivos que podem causar felicidade na população idosa caridadense é se sentir satisfeito com a vida, e conseguir pagar suas contas através de sua renda, nem que seja sem sobra de dinheiro no mês.

O Gráfico 27, diz respeito as principais necessidades ou carência dos entrevistados. $82 \%$ dos entrevistados responderam que não tem carência econômica, $18 \%$ responderam que $\operatorname{sim}$. $98 \%$ responderam que não tem carência de moradia e 2\% responderam que sim. $80 \%$ responderam que não tem carência de transporte e $20 \%$ responderam que sim. $70 \%$ responderam que não tem carência de lazer e 30\% responderam que sim. $61 \%$ responderam que tem não carência de segurança e $39 \%$ responderam que sim. $62 \%$ responderam que não tem carência de saúde e 38\% responderam que sim. $91 \%$ responderam que não tem carência de alimentação e $9 \%$ responderam que $\operatorname{sim} .76 \%$ responderam que não tem carência de companhia e contato pessoal e $24 \%$ disseram que sim.

Segundo Machado (2015), o que compromete a vida do idoso brasileiro é a falta de acesso a servidos básicos, como transporte, segurança, renda, saúde, ambiente propício para os idosos, fazem com que deixe

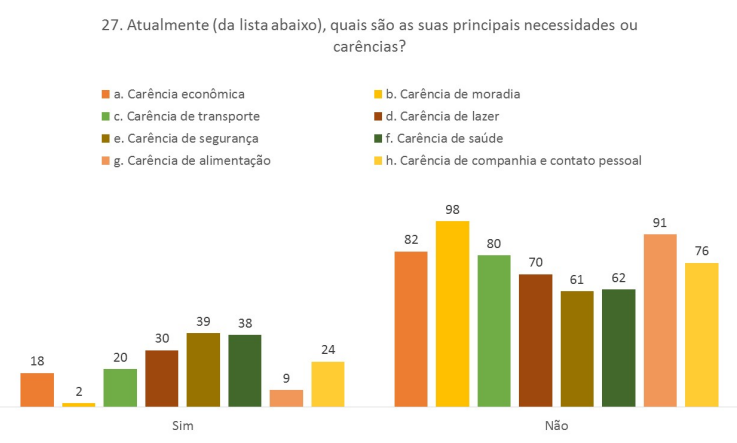

nítido que o Brasil não está preparado para o avanço populacional das pessoas que fazem parte da terceira idade. Quando comparamos o estudo de Machado com o presente estudo, nota-se a diferença de resultados, pois a maioria do idosos caridadense, não tem muitas necessidades ou carências, quando relacionado a opinião de Machado sobre a população brasileira.

O Gráfico 28, diz respeito aos problemas mais importante do dia-a-dia da pessoa idosa. $69 \%$ relataram que não existe problemas importantes e $31 \%$ responderam que $\operatorname{sim}$. $74 \%$ responderam que não tem problema econômico e $26 \%$ responderam que sim. $69 \%$ responderam que não tem problema de saúde e $31 \%$ responderam que sim. $58 \%$ responderam que não tem medo da violência e $42 \%$ responderam que sim. $89 \%$ responderam que não tem problema de moraria e $11 \%$ responderam que sim. $80 \%$ responderam que não tem problema de transporte e $20 \%$ responderam que sim. $71 \%$ responderam que não tem problemas familiares (conflitos) e $29 \%$ responderam que sim. $67 \%$ responderam que não tem problema de isolamento (solidão) e $33 \%$ responderam que sim. $58 \%$ responderam que não tem preocupação com filhos/netos e $42 \%$ responderam que sim.

Gráfico 28: Problemas mais importantes do dia-a-dia

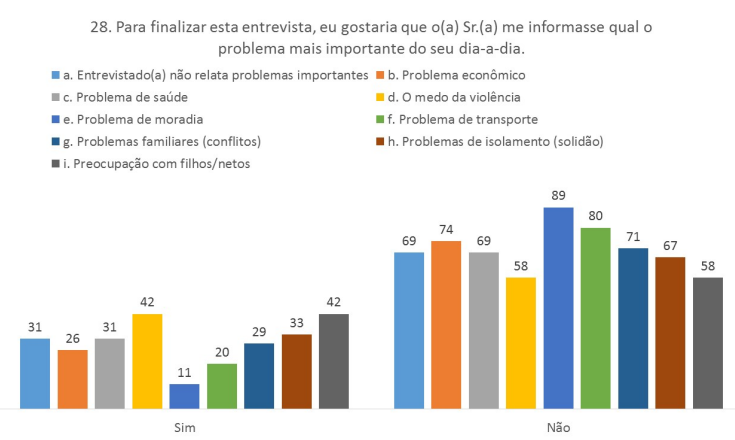


PERFIL DO IDOSO DA CIDADE DE CARIDADE-CE.

Segundo Gois (2006), a medida em que os idosos vão ganhando espaço na sociedade, sendo independentes, indo em busca de seus direitos, é notório que os mesmos não vivem nas mesmas condições dos anos 90 , a condição de vida do idoso comparado a esse período é melhor, porém isso não se significa que os mesmos terão melhores condições de vida. Quando comparamos o presente estudo com o estudo de Gois, percebe-se que a maioria dos idosos caridadenses não tem problemas consideráveis, assim diferenciando do que Gois falou em sua pesquisa, ao relatar que os idosos passaram por má qualidade de vida.

O Gráfico 29, diz respeito a quantidade de pessoas que moram com os entrevistados. $79 \%$ responderam que 01 a 05 pessoas, o restante com $21 \%$ respondeu que 06 ou mais pessoas. A maioria respondeu que moram com 01 a 05 pessoas.

Gráfico 29: Pessoa que vivem com os idosos

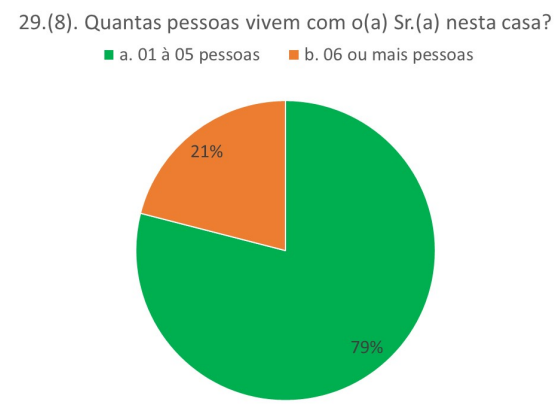

Para alguns idosos, conviver com familiares na mesma residência pode ser considerado algo essencial, na resolução de questões do cotidiano (físicas ou financeiras), assim como no compartilhamento de convivência diária (CAMARGOS et al., 2011). Quando comparamos os estudos de Camargos, Rodrigues e Machado, com o atual estudo, percebe-se semelhança em mostrar as possíveis justificativas das pessoas idosas da cidade de Caridade-CE morarem com outras pessoas e não optarem por morar sozinhos.

\section{CONSIDERAÇÕES FINAIS}

Ao final do estudo realizado pode-se perceber que o número de mulheres é superior ao número de homens no município de Caridade-CE, a sua maioria com idade entre 60 a 70 anos, na qual todos os entrevistados são cearenses. Alguns idosos compartilharam que sua cidade natal não era Caridade- $\mathrm{CE}$, mas moram nesse município desde antes de sua emancipação política.
A escolaridade dos idosos entrevistados é muito precária, na qual a maioria não nem o ensino fundamental, dificultando sua pratica na leitura e escrita onde $51 \%$ dos entrevistados não sabem ler e escrever. Os mesmos são casados ou moram juntos e têm 4 ou mais filhos, relatando estarem satisfeitos com sua vida no geral.

A maioria dos entrevistados consideram que tem uma boa saúde, porém ainda apresentam problemas na mesma, constatado em $65 \%$ dos idosos, tendo os filhos como acompanhantes para a utilização dos serviços médicos de instituições públicas gratuitas em casos de doenças ou na aquisição de medicamentos, se satisfazendo com o atendimento dessas instituições.

O sustento de vida da maioria da população idosa do município de Caridade-CE vem da aposentadoria que na maioria dos casos é a conta certa para suprir as necessidades diárias, mas vale ressaltar que para outros benefícios, o salário não é o suficiente, ocorrendo sempre a falta de recursos financeiros. Os idosos em sua maioria sentem-se satisfeitos com a convivência entre seus vizinhos, amigos e pessoas que moram na mesma residência e convivem diariamente.

Uma significativa quantidade de idosos não sentem arrependimentos por algo que já tenham feito, mostrando que são felizes e citam expectativas e planejamento para o futuro. Os idosos, especificamente os brasileiros passam por dificuldades de saúde e econômicas, mas o grande problema que os mesmos diariamente enfrenta é a luta para que os seus direitos sejam respeitados, na qual o estatuto do idoso seja seguido e os próprios idosos serem valorizados.

Os maus-tratos com os idosos não está restringido somente no ato da agressão. A falta de atenção e cuidados necessários como alimentação, medicamentos, o cuidado na saúde física e mental, a liberdade e dignidade, é considerado crime, pois viola o Art. 99 do estatuto do idoso. A parcela de idosos que dependem dos programas sociais disponibilizados pelo governo é elevada, porém não é sempre que os mesmos conseguem se enquadrar no perfil e assim acabam não participando. A presente pesquisa buscou traçar o perfil do idoso do município de Caridade-CE, subsidiando o poder público para o desenvolvimento de ações voltadas as pessoas idosas e estimulando os adolescentes e adultos a conhecerem a realidade do idoso caridadense.

\section{REFERÊNCIAS}

ARAÚJO, C. K.; CARDOSO, C. M. C.; MOREIRA, E. P.; WEGNER, E.; AREOSA, S. V. C. Vínculos familiares e sociais nas relações dos idosos. Revista Jovens Pesquisadores, v. 1, n. 1, p. 97-107, 2012. 
PERFIL DO IDOSO DA CIDADE DE CARIDADE-CE.

AZEVEDO, J. R. D. A utilização de medicamentos na terceira idade. 2017. Disponível em: $<\mathrm{http:}$ //www.saudevidaonline.com.br/artigo102.htm\&gt;> Acesso em: 11 nov. 2017.

BRASIL. Lei No 10.741. [S.1.], 2003.

Envelhecimento ativo: uma política de saúde. Brasília, 2005.

Resolução No 466, de 12 de dezembro de 2012. [S.l.], 2012.

CAMARGOS, M. C. S.; RODRIGUES, R. N.; MACHADO, C. J. et al. Idoso, família e domicílio: uma revisão narrativa sobre a decisão de morar sozinho. Revista Brasileira de Estudos de População: Rio de Janeiro, SciELO Brasil, v. 28, n. 1, p. 217-230, jan./jun. 2011.

CEDENHO, C. A. O idoso como novo personagem da atual sociedade: o Estatuto do Idoso e as diretrizes para o envelhecimento no Brasil. 2014. Disponível em: <https://www.metodista.br/revistas/ revistas-ims/index.php/RFD/article/view/5250/434>. Acesso em: 20 nov. 2017.

Constituição Federal. Art. 208. 1988. Disponível em: <http://www.senado.leg.br/atividade/const/con1988/ con1988_04.10.2017/art_208_.asp> Acesso em: 17 fev. 2019.

COSTA, A. E.; MADEIRA, L. M. O relacionamento do idoso com os seus familiares. Revista da Escola de Enfermagem da USP, v. 28, n. 1, p. 83-95, 1994.

COSTA, M. E.; SOUZA, J. C. P. O IDOSO NO SÉCULO XXI. 2013. Disponível em: <http://www. amog.org.br/amogarquivos/TCCPOS-TURMA-2012/ Maria-Ercilia-da-Costa.pdf> Acesso em: 20 nov. 2017.

COSTA, M. F. L.; BARRETO, S. M.; GIATTI, L. Condições de saúde, capacidade funcional, uso de serviços de saúde e gastos com medicamentos da população idosa brasileira: um estudo descritivo baseado na pesquisa nacional por amostra de domicílios. Cadernos de Saúde Pública, SciELO Public Health, v. 19, n. 1, p. 735-743, 2003.

DIAS, A. M. O processo de envelhecimento humano e a saúde do idoso nas práticas curriculares do curso de fisioterapia da UNIVALI campus Itajaí: um estudo de caso. 2007. 189 f. Dissertação (Mestrado) — Universidade do Vale do Itajai, Itajai, 2007.
DIB, C. E. dib, cybelle elias. [S.1.]: UNIMEP, 2006.

EVANS, L. Alta do custo de vida consume renda dos idosos. 2015. Disponível em: <https://www.em.com.br/app/noticia/ economia/2015/05/04/internas_economia,643622/ dragao-queima-ainda-mais-a-renda-dos-idosos. shtml> Acesso em: 13 nov. 2017.

GERHARDT, T. E.; SILVEIRA, D. T. Métodos de Pesquisa. 1. ed. Rio Grande do SuL: Universidade Federal do Rio Grande do Sul, 2009.

GOIS, A. Idosos vivem mais e melhor diz estudos. 2006. Disponível em: <http://www1.folha.uol.com.br/ folha/cotidiano/ult95u126135.shtm> Acesso em: 13 nov. 2017.

IBGE. Instituto Brasileiro de Geografia e Estatística. 2012. Disponível em: <https://ww2.ibge.gov.br/home/ presidencia/noticias/25072002pidoso.shtm> Acesso em: 17 fev. 2019.

Jacob Filho. Terceira Idade Saúde na terceira idade. 2017. Disponível em: <http://saudetotal.com.br/ artigos/idoso/terceiraidade.asp $>$. Acesso em: 11 nov. 2017.

JEREMIAS, D. Idosos dão conselhos para quem quer chegar na velhice sem aarrependimentos. 2015. Disponível em: <https://www.google.com.br/ amp/s/m.megacurioso.com.br/amp/comportamento/ 85789-idosos-dao-conselhos-para-quem-quer-chegarl -a-velhice-sem-arrependimentos.htm> Acesso em: 13 nov. 2017.

LAVOR, T. Ceará é o quinto Estado com maior percentual de idosos. 2012. Disponível em: <http:// diariodonordeste.verdesmares.com.br/cadernos/cidade/ ceara-e-o-quinto-estado-com-maior-percentual-de-idosos- 1 . 627959> Acesso em: 09 nov. 2017.

LIMA, M. G.; BARROS, M. B. d. A.; ALVES, M. C. G. P. Sentimento de felicidade em idosos: uma abordagem epidemiológica, isa-camp 2008. Cadernos de Saúde Pública, SciELO Public Health, v. 28, n. 1, p. 2280-2292, 2012.

MACHADO, R. Terceira idade no Brasil ainda tem desafios. 2015. Disponível em: <https://www.uai. com.br/app/noticia/saude/2015/09/10/noticias-saude, 187086/terceira-idade-no-brasil-ainda-tem-desafios. shtml> Acesso em: 13 nov. 2017. 
PERFIL DO IDOSO DA CIDADE DE CARIDADE-CE.

MENDES, L. d. D. S. Visão e envelhecimento. 2008. Disponível em: <http://www.dbd.puc-rio.br/ pergamum/tesesabertas/0610650_08_cap_03.pdf> Acesso em: 11 nov. 2017.

NANÔ, F. Mulheres são maioria no país, diz IBGE: desigualdade é maior no Sudeste. 2012. Disponível em: <https://noticias.uol. com.br/cotidiano/ultimas-noticias/2012/09/21/ mulheres-sao-maioria-no-pais-mas-proporcaol -com-os-homens-e-igual-no-norte.htm> Acesso em: 07 nov. 2017.

PEREIRA, D. Coleção Redação ENEM: Chego Junto, Chego a 1000! [S.1.], 2017.

PERES, M. A. D. C. Velhice e analfabetismo, uma relação paradoxal: a exclusão educacional em contextos rurais da região Nordeste. 1 . ed. Brasília: Soc.Estado, 2011.

RAMOS, M. Apoio social e saúde entre idosos. 1. ed. Porto Alegre: Sociologias, 2002.

ROSA, G. O envelhecimento do século XXI 2015. Disponível em: <https://www.projetoredacao. com.br/temas-de-redacao/o-que-e-uma-familia/ o-envelhecimento-do-seculo-xxi/1976> Acesso em: 14 nov. 2017.

SARAIVA, A. IBGE: Brasil tem mais pessoas casadas que solteiras. 2010. Disponível em: $<$ http://www.estadao.com.br/noticias/geral, ibge-brasil-tem-mais-pessoas-casadas-que-solteiras, 606735> Acesso em: 10 nov. 2017.

SOUZA, D. S.; NORONHA, M. D. S.; SILVA, K. S. P. Novas configurações familiares. 2016. Disponível em: $<$ http://www.ambito-juridico.com.br/site/index.php? n_link=revista_artigos_leitura\&artigo_id=17678> Acesso em: 10 nov. 2017.

Sé, E. V. G. Independente da idade, otimistas em relação ao futuro têm sensação que o tempo passa rápido. 2015. Disponível em: <http://vyaestelar.uol.com.br/post/6357/ independente-da-idade-otimistas-em-relacao-aol -futuro-tem-sensacao-que-o-tempo-passa-rapido? /otimismo_futuro.htm>. Acesso em: 13 nov. 2017.

TEIXEIRA, S. M. Lazer e tempo livre na "terceira idade": potencialidades e limites no trabalho social com idosos. Revista Kairós: Gerontologia, v. 10, n. 2, p. 169-188, 2007.
VALE, N. Solidão e sensação de inutilidade comprometem a saúde dos idosos: Doenças como hipertensão e fibromialgia, com causas emocionais, são comuns na velhice. 2010. Disponível em: <http://www.minhavida.com.br/saude/materias/ 11219-solidao-e-sensacao-de-inutilidade-comprometem -a-saude-dos-idosos> Acesso em: 10 nov. 2017.

VERAS, R. Perfil do idoso brasileiro: questionário BOAS. 1. ed. Rio de Janeiro: UERJ, UnATI, 2008. 